\title{
An Epidemiological Study of Hemodialysis Patients Based on the European Fresenius Medical Care Hemodialysis Network: Results of the ARO Study
}

\author{
Angel L.M. de Francisco ${ }^{\mathrm{a}}$ Joseph Kim ${ }^{\mathrm{b}}$ Stefan D. Anker ${ }^{\mathrm{c}}$ Vasily Belozeroff $^{\mathrm{d}}$ Bernard Canaud $^{\mathrm{e}}$ \\ Charles Chazot $^{f}$ Tilman B. Drüeke ${ }^{g}$ Kai-Uwe Eckardt ${ }^{\text {h }}$ Jürgen Floege ${ }^{i}$ Florian Kronenberg ${ }^{j}$ \\ Iain C. Macdougallk ${ }^{k}$ Daniele Marcelli' Bart Molemans ${ }^{m}$ Jutta Passlick-Deetjen' \\ Guntram Schernthaner $^{\mathrm{n}}$ Peter Stenvinkel $^{\mathrm{o}}$ David C. Wheeler $^{\mathrm{p}}$ Bruno Fouqueray $^{\mathrm{q}}$ \\ Pedro Aljamar \\ a Servicio de Nefrologia, Hospital Universitario Valdecilla, Santander, Spain; 'bepartment of Epidemiology, Amgen Ltd., \\ Uxbridge, UK; ' ${ }^{\mathrm{D}}$ Department of Cardiology, Applied Cachexia Research, Campus Virchow Klinikum, Charité, Berlin, Germany, \\ and Center for Clinical and Basic Research, IRCCS San Raffaele, Rome, Italy; ${ }^{d}$ Department of Health Economics, Amgen Inc.,

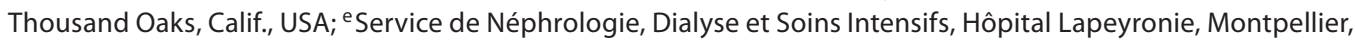 \\ ${ }^{f}$ Centre de Rein Artificiel, Tassin-la-Demi-Lune, et ${ }^{9}$ Facultés de Médecine et de Pharmacie, Université de Picardie,

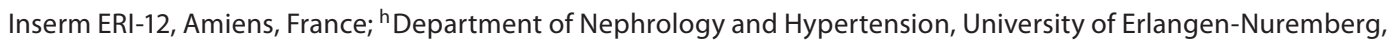 \\ Erlangen, and 'Division of Nephrology, RWTH University of Aachen, Aachen, Germany; 'Division of Genetic Epidemiology,

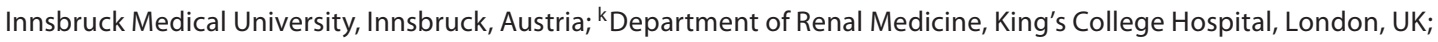 \\ 'Department of NephroCare Coordination, Fresenius Medical Care, Bad Homburg, Germany; ${ }^{m}$ Department of Nephrology, \\ Amgen Ltd., Uxbridge, UK; ${ }^{n}$ Department of Medicine I, Rudolfstiftung Hospital, Vienna, Austria; ${ }^{\circ}$ Department of \\ Renal Medicine, Karolinska Institute, Stockholm, Sweden; ${ }^{P}$ Center for Nephrology, Royal Free Campus, University \\ College London Medical School, London, UK; ' ${ }^{9}$ Department of Nephrology, Amgen (Europe) GmbH, Zug, Switzerland; \\ 'Department of Nephrology, Hospital Reina Sofia de Cordoba, Cordoba, Spain
}

\section{Key Words}

Anemia $\cdot$ Epidemiology $\cdot$ Hemodialysis $\cdot$ Mineral disorders $\cdot$ Mortality, practice patterns

\section{Abstract \\ Background/Aims: ARO, an observational study of hemodi- alysis (HD) patients in Europe, aims to enhance our under- standing of patient characteristics and practice patterns to improve patient outcome. Methods: HD patients ( $n=8,963$ ) from 134 Fresenius Medical Care facilities treated between 2005 and 2006 were randomly selected from 9 European}

Except for V.B., all authors are ARO-CKD Research Initiative Steering Committee Members.
(C) 2010 S. Karger AG, Base $1660-2110 / 11 / 1182-0143 \$ 38.00 / 0$

Fax +41613061234 E-Mail karger@karger.ch www.karger.com countries (Czech Republic, France, Hungary, Italy, Poland, Portugal, Spain, Slovak Republic and Slovenia) and Turkey. Information was captured on demographics, comorbidities, medications, laboratory and dialysis parameters, and outcome. Results: Patients were followed for $1.4 \pm 0.7$ years. Wide variation by country was observed for age, sex and diabetes as a cause of chronic kidney disease. Cardiovascular disease was present in $73 \%$ of patients. Dialysis parameters were homogeneous across countries. Arteriovenous fistulas were frequently used (73\%). More incident patients had hemoglobin $<11 \mathrm{~g} / \mathrm{dl}$ than prevalent patients (50 vs. 33\%, respectively). Phosphatemia and intact parathyroid hormone were similar between incident and prevalent patients (4.7 \pm $1.2 \mathrm{mg} / \mathrm{dl}$ and $190 \mathrm{vs.} 213 \mathrm{ng} / \mathrm{l}$, respectively). Medication use varied widely by country. In total, $5 \%$ of patients underwent renal transplantation. Overall death rate was $124 / 1,000$ pa-

A.L.M. de Francisco

Servicio de Nefrología

Hospital Universitario Marqués Valdecilla

ES-39008 Santander (Spain)

Tel. +34 942202 738, Fax +34 942320 415, E-Mail martinal@unican.es 
tient-years. Conclusion: ARO revealed differences in HD practice patterns and patient characteristics in the 10 participating countries. Future ARO studies will fill gaps in the knowledge about the care of European HD patients.

Copyright $\odot 2010$ S. Karger AG, Basel

\section{Introduction}

Significant progress has been made in the care of patients with chronic kidney disease (CKD) over recent decades. Nevertheless, the prevalence of CKD requiring dialysis has been steadily increasing $[1,2]$, and the mortality rate in patients undergoing hemodialysis (HD) remains high [3]. Several epidemiological studies have been conducted in the United States to evaluate the patterns of clinical practice, the achievement of treatment guidelines and the occurrence of outcome in HD patients [4-7]. Due to the lack of other available data, the results have been extrapolated to other populations despite known differences in patient characteristics $[3,8,9]$ and clinical practice patterns [9].

The only population-based study published to date that captures both US and European HD populations is the Dialysis Outcome and Practice Patterns Study (DOPPS) $[4,8,10-12]$. However, the generalizability of these results to the wider European HD population may be limited since only patients from Western Europe were selected. Other population-based studies have been carried out in European HD patients, including NECOSAD (Netherlands Cooperative Study on the Adequacy of Dialysis) [13-15] and COSMOS [16]. However, their findings may be limited since NECOSAD is a single-country study and COSMOS focuses on issues related to bone and mineral disorders. The ARO (Analyzing Data, Recognizing Excellence and Optimizing Outcome) CKD Research Initiative began in 2007 to improve HD patient outcome through better understanding of patient characteristics and practice of care in Europe. This study is based on a clinical database from European Fresenius Medical Care (EU-FME) dialysis centres. A unique strength of this study is that it includes not only patients from Western Europe but also patient populations from Eastern Europe and Turkey who have been largely neglected in other studies.

The aims of this report are to present the design and methodology of the ARO-CKD Research Initiative, and describe the population currently investigated with respect to patient characteristics, dialysis and biochemical parameters, medication use and patient outcome.

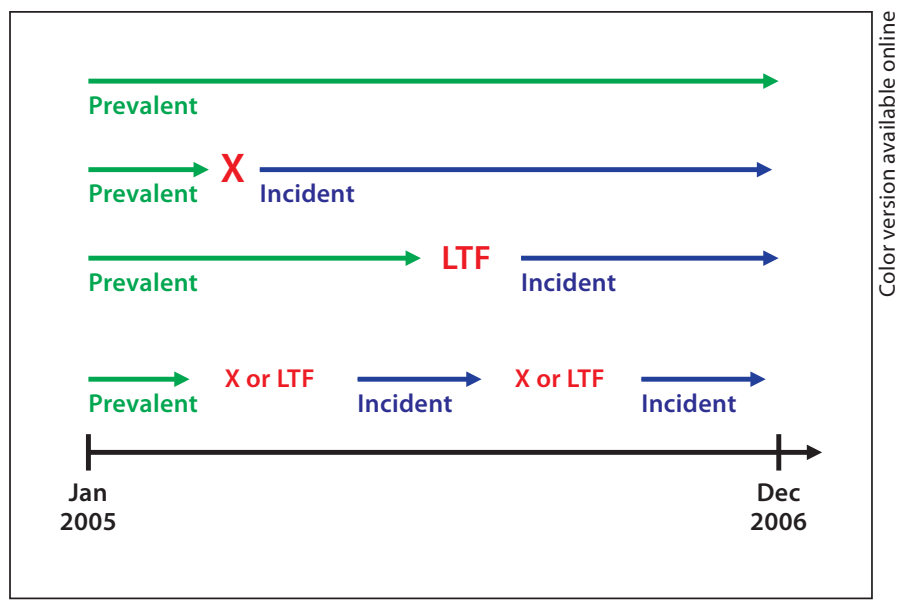

Fig. 1. Open-cohort study design. The study includes incident $(<6$ months of dialysis at the time of enrolment) and prevalent ( $\geq 6$ months of dialysis) hemodialysis patients. A prevalent dialysis patient who died or experienced a censoring event (lost to follow-up or successful renal transplant) over the course of the study was replaced with a randomly selected incident patient from the same dialysis facility. $\mathrm{X}=\mathrm{An}$ event (e.g. death or successful renal transplant); LTF $=$ a patient lost to follow-up.

\section{Subjects and Methods}

Source Population

The source population consisted of patients who underwent HD at selected FME facilities between the 1st of January 2005 and the 31st of December 2006. Anonymized patient data were captured using the European Clinical Database (EuCliD), which has been described elsewhere [17-19]. Informed consent was obtained from all patients by FME.

\section{Selection of Participants}

Patients were selected into this study using an open-cohort design [20] because it allowed the selection of a heterogeneous mix of patients (i.e. incident and prevalent dialysis patients). In addition, it maintained a fixed period of follow-up (i.e. 15,000 patient-years): each patient who died or experienced a censoring event (i.e. lost to follow-up or successful renal transplant) was replaced with a randomly selected incident patient from the same facility. Incident patients had undergone HD for less than 6 months at the start of the study; prevalent patients had undergone HD for 6 months or longer (fig. 1).

A random sample of HD patients was selected by (1) defining geographic strata based on the number of FME facilities within specific countries on January 1, 2005; (2) selecting a random sample of eligible facilities within each stratum, and (3) randomly selecting patients from these facilities. Eligible facilities were part of FME for at least 12 months prior to January 1, 2005, and remained in the network on December 31, 2006. Each center must have treated at least 25 patients as of December 1, 2005. A maximum of 25 sites were eligible for random selection within each country. Twenty-five sites were randomly chosen in Portugal and 
Spain due to the higher number of centers; all eligible sites were included elsewhere. In total, patients were selected from $172 \mathrm{fa}$ cilities in 11 countries (Czech Republic, France, Hungary, Italy, Poland, Portugal, Spain, Slovak Republic, Slovenia, Turkey and the United Kingdom).

A total of 11,153 patients (7,037 prevalent and 4,116 incident patients) were sampled and contributed approximately $15,000 \mathrm{pa}-$ tient-years of observation over a 2-year follow-up period (January 2005 to December 2006).

\section{Variables of Interest}

Demographic characteristics available for this study included age, gender, smoking history, height and weight both before and after dialysis. Information on medical history included the etiology of CKD, history of cardiovascular disease (CVD; defined as peripheral vascular disease, congestive heart failure, coronary artery disease, myocardial infarction, and/or angina, cerebrovascular accident and/or transient ischemic attack), history of diabetes (defined as a recorded history of diabetes or use of diabetic medication) and history of cancer.

Detailed information on dialysis vintage, dialysis access [arteriovenous (AV) fistula, AV graft, and temporary or permanent venous catheter], actual blood flow and dialysis adequacy (singlepool Kt/V) [21] was also obtained. All dialyzers were single use. Information on the dialyzer type was not available.

Laboratory data included circulating markers for anemia (hemoglobin and ferritin), bone and mineral metabolism [total calcium, phosphate and intact parathyroid hormone (iPTH)], lipid metabolism (cholesterol, high- and low-density cholesterol) and inflammation (C-reactive protein and albumin). There was no standard assay method to evaluate PTH.

Information on medication use included the name of the product, duration of use and the weekly dose. Data were available on phosphate binders, oral vitamin D (data on intravenous vitamin $\mathrm{D}$ were not available), calcimimetics, erythropoietin-stimulating agents (ESA), platelet inhibitors, statins, anti-hypertensives (including angiotensin-converting enzyme inhibitors and angiotensin receptor blockers), oral anticoagulants, insulin and oral antidiabetics.

Outcome data were available for hospitalization, renal transplantation and death. Reasons for hospitalization and cause of death were coded according to the WHO International Classification of Diseases (10th Revision; ICD-10) coding scheme. Patients were considered lost to follow-up if they left a dialysis facility and failed to return within 45 days.

\section{Statistical Analysis}

Normally distributed variables were described using means and standard deviations; medians and interquartile ranges were used otherwise. Where appropriate, variables were grouped into clinically meaningful classes for further analysis. Bivariate comparisons were performed using Student's t test, a Wilcoxon rank sum test or a $\chi^{2}$ test as appropriate. Mortality and hospitalization rates were calculated using Poisson regression. Adjusted mortality rates were derived by including age, gender and duration of dialysis treatment as covariates in the model.

Dialysis parameters, laboratory parameters and medication use were calculated based on the average monthly values recorded and reported as the average 6-month value.

Epidemiological Study - European

Hemodialysis Patients
All statistical analyses were performed using SAS for Windows (version 9.0; SAS, Cary, N.C., USA) and were reproduced independently by a second statistician.

\section{Results}

Of the 11,153 patients selected into the study, we excluded patients recruited from centers where the majority of data on key dialysis parameters (i.e. actual blood flow or Kt/V) were missing $(\mathrm{n}=1,352)$. UK patients were also excluded because information on medication was not available $(\mathrm{n}=838)$. The remaining 8,963 patients (3,396 incident and 5,567 prevalent patients) were included in the analysis. Patients were followed for $1.4 \pm 0.7$ years (incident patients: $1.0 \pm 0.6$ years, and prevalent patients: $1.6 \pm 0.6$ years), contributing to 12,194 patientyears of follow-up.

\section{Demographics and Baseline Characteristics}

Spain $(\mathrm{n}=1,707)$, Turkey $(\mathrm{n}=1,600)$ and Italy $(\mathrm{n}=$ 1,586) contributed the largest numbers of patients to the overall cohort (table 1). The youngest patients were from Turkey (56 \pm 15 years) and the oldest patients from France (69 \pm 15 years). The most common CKD etiology was glomerulonephritis (16\%), followed by tubulointerstitial nephritis (14\%), diabetic nephropathy (14\%) and hypertension (13\%). A history of CVD was present in $73 \%$ of patients (50\% incident and $87 \%$ prevalent patients), ranging from $64 \%$ in France to $91 \%$ in Slovenia. The prevalence of diabetes was $25 \%$, which varied by country from $15 \%$ in Spain to $42 \%$ in the Czech Republic.

\section{Dialysis Parameters}

Prevalent patients had undergone HD on average for 5 years prior to study entry (table 2 ). The mean actual blood flow in prevalent patients was $313 \pm 48 \mathrm{ml} / \mathrm{min}$, ranging from $260 \pm 35 \mathrm{ml} / \mathrm{min}$ in Slovenia to $349 \pm 48 \mathrm{ml} / \mathrm{min}$ in Italy. Mean actual blood flow was higher in prevalent than incident patients ( $313 \mathrm{vs.} 283 \mathrm{ml} / \mathrm{min}$ ). Kt/V ranged from $1.4 \pm 0.3$ in Hungary and Poland to $1.8 \pm 0.3$ in the Czech Republic. Consistent with the findings for actual blood flow, Kt/V was higher among prevalent patients than incident patients $(1.7 \pm 0.3$ vs. $1.5 \pm 0.3$, respectively). An AV fistula was the preferred mode of vascular access compared with AV graft or venous catheter across each country. Prevalent patients were significantly more likely to be dialyzed with an AV fistula than incident patients (78 vs. $64 \%$ ). 
Table 1. Patient baseline characteristics by country

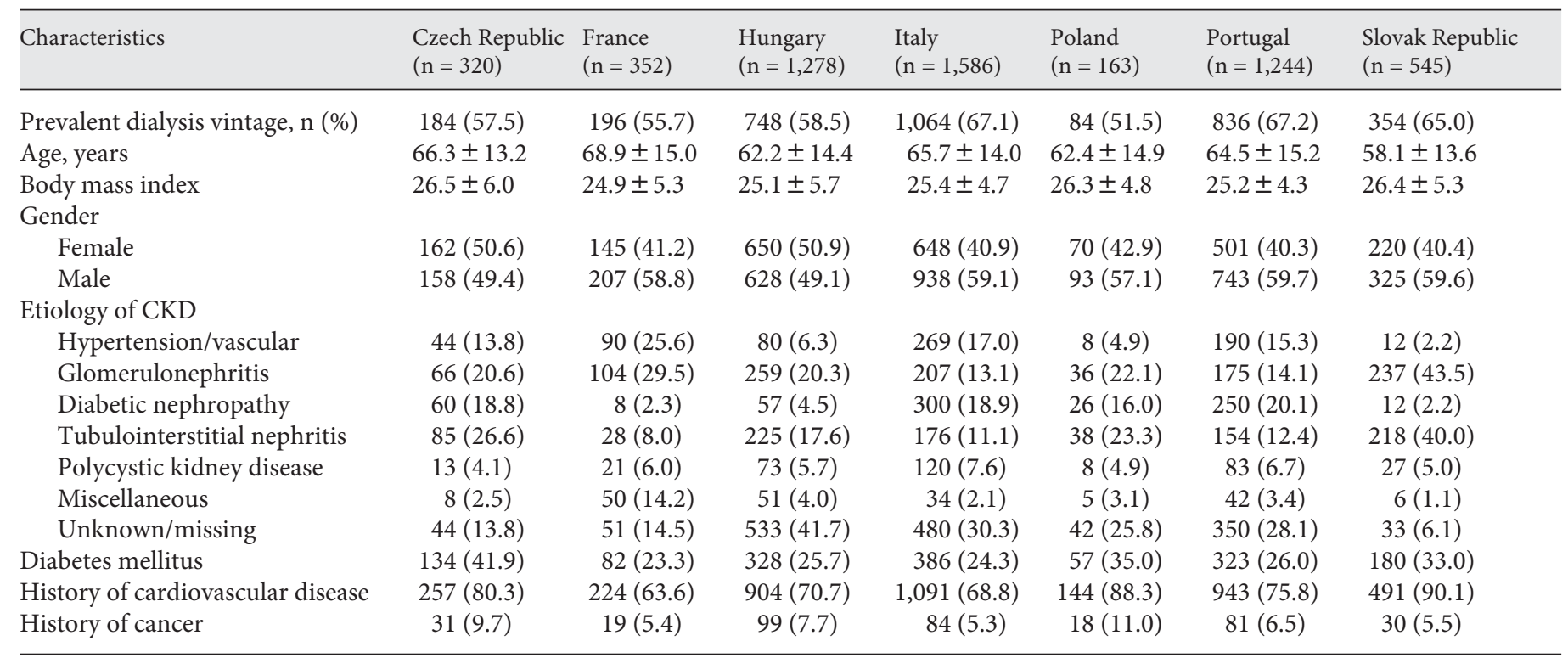

Baseline includes the 6 months of data collection for any parameter measured. Continuous variables are reported using means \pm $\mathrm{SD}$. Categorical variables are reported as $\mathrm{n}(\%)$. Prevalent dialysis vintage was defined as having undergone $>6$ months of hemodialysis at the start of the study. Miscellaneous = Rare causes of CKD with no standard diagnosis; missing $=$ the cause of CKD was not recorded; unknown $=$ the cause of CKD is unknown. The tabulation for cardiovascular disease (any) includes outcome according to identified ICD10 codes (angina, coronary artery disease, myocardial infarction, congestive heart failure, peripheral vascular disease and cerebrovascular accident).

Table 2. Distribution of dialysis parameters during the first 6 months of follow-up by dialysis vintage and country

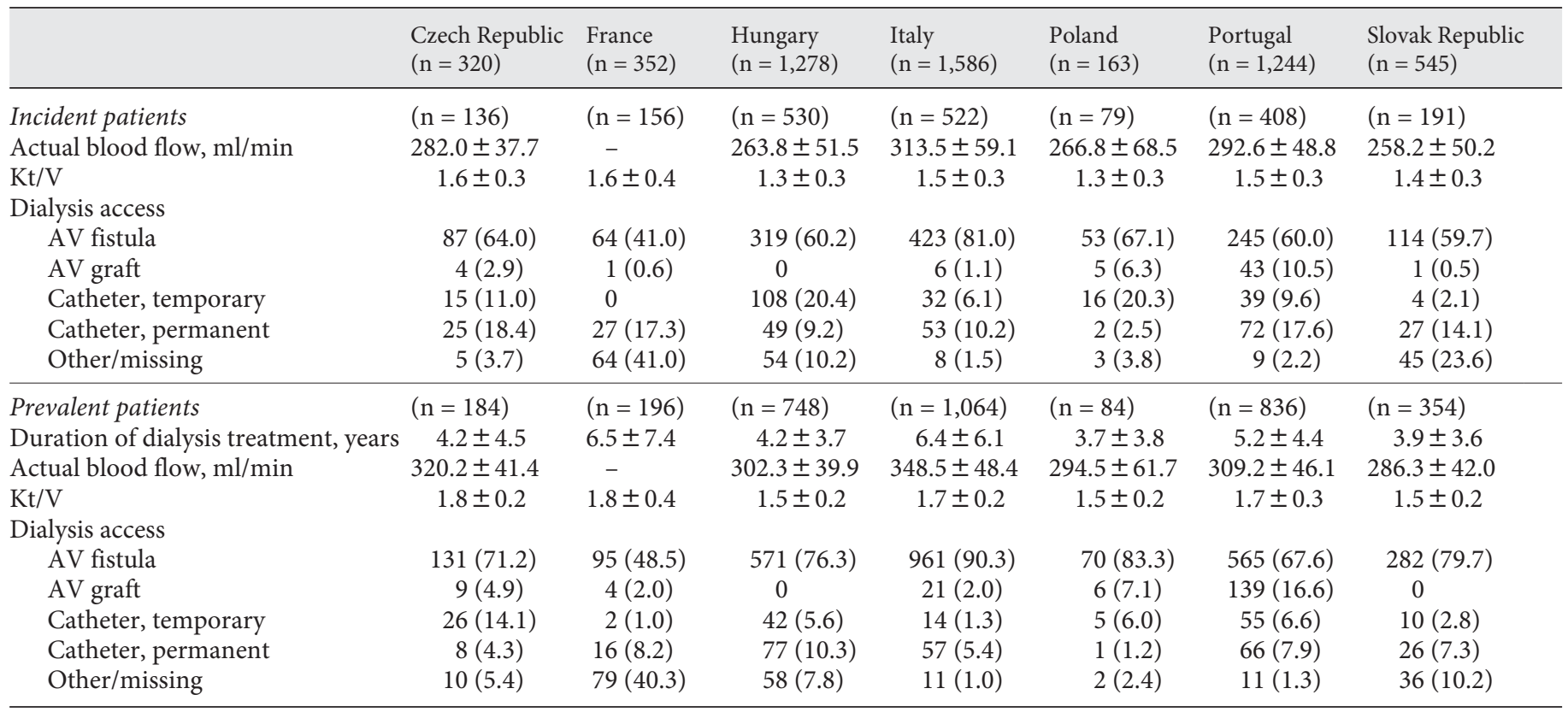

Continuous variables are reported using means $\pm \mathrm{SD}$. Categorical variables are reported using $\mathrm{n}(\%) .-=$ Missing data; $\mathrm{K}=$ dialyzer clearance of urea; $\mathrm{t}=$ dialysis time; $\mathrm{V}=$ patient's total body water. Incident patients were on HD therapy $<6$ months at the start of the study; prevalent patients were on HD therapy for $\geq 6$ months. The last mode of dialysis access used at the 6 -month follow-up is listed. 


\begin{tabular}{cccc}
\hline $\begin{array}{l}\text { Slovenia } \\
(\mathrm{n}=168)\end{array}$ & $\begin{array}{l}\text { Spain } \\
(\mathrm{n}=1,707)\end{array}$ & $\begin{array}{l}\text { Turkey } \\
(\mathrm{n}=1,600)\end{array}$ & $\begin{array}{l}\text { Total } \\
(\mathrm{n}=8,963)\end{array}$ \\
\hline $130(77.4)$ & $897(52.5)$ & $1,074(67.1)$ & $5,567(62.1)$ \\
$64.0 \pm 12.2$ & $65.9 \pm 14.6$ & $56.4 \pm 14.5$ & $63.0 \pm 14.9$ \\
$26.5 \pm 5.0$ & $25.3 \pm 4.8$ & $24.8 \pm 4.5$ & $25.4 \pm 4.8$ \\
& & & \\
$75(44.6)$ & $636(37.3)$ & $705(44.1)$ & $3,812(42.5)$ \\
$93(55.4)$ & $1,071(62.7)$ & $895(55.9)$ & $5,151(57.5)$ \\
& & & \\
$17(10.1)$ & $163(9.5)$ & $316(19.8)$ & $1,189(13.3)$ \\
$42(25.0)$ & $232(13.6)$ & $111(6.9)$ & $1,469(16.4)$ \\
$24(14.3)$ & $109(6.4)$ & $371(23.2)$ & $1,217(13.6)$ \\
$38(22.6)$ & $145(8.5)$ & $125(7.8)$ & $1,232(13.7)$ \\
$13(7.7)$ & $71(4.2)$ & $57(3.6)$ & $486(5.4)$ \\
$5(3.0)$ & $115(6.7)$ & $46(2.9)$ & $362(4.0)$ \\
$29(17.3)$ & $872(51.1)$ & $574(35.9)$ & $3,008(33.6)$ \\
$41(24.4)$ & $263(15.4)$ & $448(28.0)$ & $2,242(25.0)$ \\
$153(91.1)$ & $1,241(72.7)$ & $1,086(67.9)$ & $6,534(72.9)$ \\
$17(10.1)$ & $145(8.5)$ & $31(1.9)$ & $555(6.2)$ \\
\hline
\end{tabular}

\section{Hemoglobin}

The mean hemoglobin value achieved was $11.3 \mathrm{~g} / \mathrm{dl}$, ranging from $10.4 \mathrm{~g} / \mathrm{dl}$ in the Slovak Republic to $11.9 \mathrm{~g} / \mathrm{dl}$ in the Czech Republic, Slovenia and Spain (table 3). Incident patients were more likely to have a hemoglobin level $<11 \mathrm{~g} / \mathrm{dl}$ (50 vs. $33 \%$ ) and were less likely to have a hemoglobin level $>13 \mathrm{~g} / \mathrm{dl}$ than prevalent patients (7 vs. $12 \%$ ).

\section{Other Laboratory Parameters}

Table 4 shows that prevalent patients had higher levels of total serum calcium than incident patients $(9.2 \pm 0.9$ vs. $8.9 \pm 0.8 \mathrm{mg} / \mathrm{dl}$, respectively). Phosphatemia was similar in incident and prevalent patients $(4.7 \pm 1.2 \mathrm{mg} / \mathrm{dl})$ despite wide variation across countries. iPTH values were comparable in incident and prevalent patients (190 vs. 213 $\mathrm{ng} / \mathrm{l})$.

Ferritin levels were consistently higher in prevalent patients than incident patients ( $475 \mathrm{vs.} 267 \mu \mathrm{g} / \mathrm{l}$, respectively). C-reactive protein levels were relatively comparable between incident and prevalent patients, whereas serum albumin levels were higher in prevalent than incident patients, with a wide variation by country $(3.9 \pm 0.5$ vs. $3.7 \pm 0.5 \mathrm{~g} / \mathrm{dl}$, respectively).

\section{Medication Use}

Statin use varied widely and the prevalence was generally low (13\%). Angiotensin-converting enzyme inhibitor or angiotensin receptor blocker use ranged from $6 \%$ in Turkey to $41 \%$ in Poland, while less than one third of patients were treated with another anti-hypertensive drug. At least $76 \%$ of patients were on ESA therapy, with the exception of Turkey (59\%; table 5). In addition, incident patients were more likely to have received ESA than prevalent patients (82 vs. 76\%). The frequency of phosphate binder use ranged from $24 \%$ in Italy to $76 \%$ in Poland and the type varied by country. Likewise, the use of oral vitamin D sterols differed widely across the countries (from $3 \%$ in Turkey to $52 \%$ in the Czech Republic).

\section{Patient Outcome}

During the study period (2005-2006), there were 1,678 deaths, $42 \%$ of which were attributed to CVD (table 6). The overall crude mortality rate was 138 deaths per 1,000 patient-years, which was higher for incident than for prevalent patients (158 vs. 130 deaths per 1,000 patientyears). When adjusted for age, gender and duration of dialysis, the death rate was 124 per 1,000 patient-years, ranging from 73 (Slovenia) to 182 per 1,000 patient-years (Slovak Republic). 
Table 3. Achieved hemoglobin levels during the first 6 months of follow-up by dialysis vintage and country

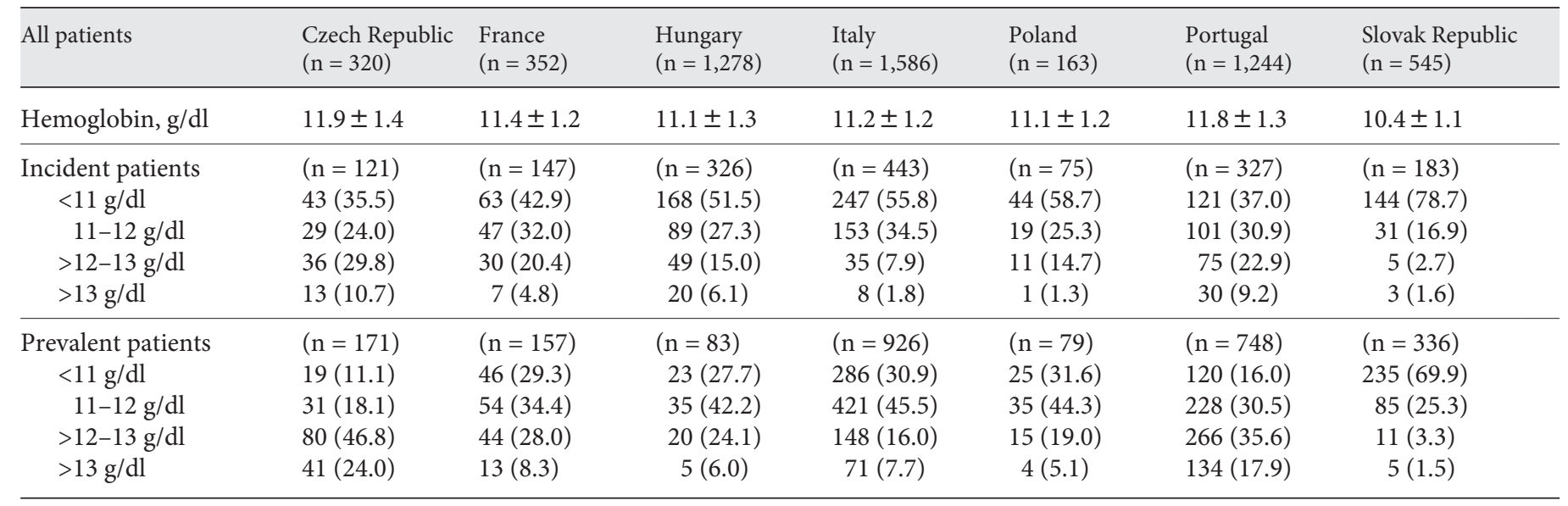

Continuous variables are reported using means \pm SD. Categorical variables are reported as $\mathrm{n}(\%)$. Incident patients were on HD therapy $<6$ months at the start of the study; prevalent patients were on HD therapy for $\geq 6$ months. Reported values of achieved hemoglobin levels were calculated using average monthly values of hemoglobin.

Table 4. Laboratory parameters during the first 6 months of follow-up by country

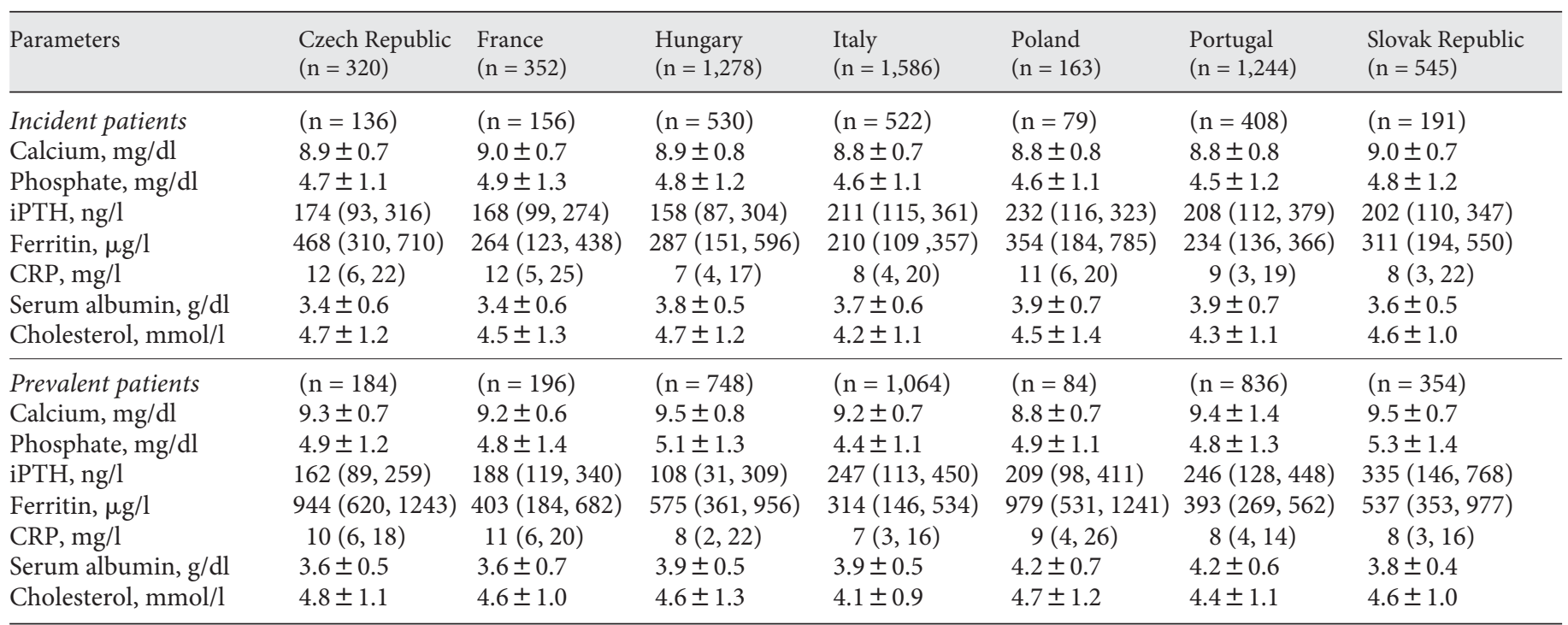

Incident patients were on HD therapy $<6$ months at the start of the study; prevalent patients were on HD therapy for $\geq 6$ months. All values are reported using means $\pm \mathrm{SD}$, except for $\mathrm{iPTH}$, ferritin and $\mathrm{C}$-reactive protein $(\mathrm{CRP})$, where medians (interquartile ranges) are reported (conversion for $\mathrm{mg} / \mathrm{dl}$ to $\mathrm{mmol} / \mathrm{l}$ : multiply by 0.2495 ).

A total of 3,254 patients had at least one hospitalization episode during the course of follow-up. The first hospitalization rate was 344 events per 1,000 patient-years and was higher for incident patients than for prevalent patients (445 vs. 306 events per 1,000 patient-years).
Nearly $5 \%(438 / 8,963)$ of patients had a successful renal transplant during the study, ranging from $1.8 \%$ in Turkey to $7.9 \%$ in Spain. Twelve percent $(1,058 / 8,963)$ of patients were lost to follow-up; $65 \%(5,789 / 8,963)$ of patients completed the study. 


\begin{tabular}{clcc}
\hline $\begin{array}{l}\text { Slovenia } \\
(\mathrm{n}=168)\end{array}$ & $\begin{array}{l}\text { Spain } \\
(\mathrm{n}=1,707)\end{array}$ & $\begin{array}{l}\text { Turkey } \\
(\mathrm{n}=1,600)\end{array}$ & $\begin{array}{l}\text { Total } \\
(\mathrm{n}=8,963)\end{array}$ \\
\hline $11.9 \pm 1.0$ & $11.9 \pm 1.4$ & $10.6 \pm 1.4$ & $11.3 \pm 1.4$ \\
\hline$(\mathrm{n}=37)$ & $(\mathrm{n}=703)$ & $(\mathrm{n}=421)$ & $(\mathrm{n}=2,783)$ \\
$8(21.6)$ & $227(32.3)$ & $327(77.7)$ & $1,392(50.0)$ \\
$18(48.6)$ & $204(29.0)$ & $71(16.9)$ & $762(27.4)$ \\
$9(24.3)$ & $166(23.6)$ & $18(4.3)$ & $434(15.6)$ \\
$2(5.4)$ & $106(15.1)$ & $5(1.2)$ & $195(7.0)$ \\
\hline$(\mathrm{n}=130)$ & $(\mathrm{n}=810)$ & $(\mathrm{n}=935)$ & $(\mathrm{n}=4,375)$ \\
$14(10.8)$ & $122(15.1)$ & $535(57.2)$ & $1,425(32.6)$ \\
$47(36.2)$ & $225(27.8)$ & $244(26.1)$ & $1,405(32.1)$ \\
$54(41.5)$ & $272(33.6)$ & $92(9.8)$ & $1,002(22.9)$ \\
$15(11.5)$ & $191(23.6)$ & $64(6.8)$ & $543(12.4)$ \\
\hline
\end{tabular}

and Turkey suggest that patient characteristics and treatment patterns vary widely across Europe, which may be explained in part by differences in comorbid conditions, availability of healthcare resources and variability in physician training.

For instance, there was a wide age distribution across the 10 countries, the mean age ranging from 56 years in Turkey to 69 years in France. We also found that overall the proportion of patients with glomerulonephritis as the primary cause of CKD (16\%) was comparable to previous findings [22]. The diagnosis of CKD etiology, however, was somewhat inconsistent within the cohort: only $2 \%$ of patients in the Slovak Republic had a diagnosis of diabetic nephropathy despite a $33 \%$ prevalence of diabetes. Likewise in the Czech Republic, 19\% had diabetic nephropathy while $42 \%$ of patients had diabetes. The discrepancy between diabetic nephropathy as the etiology of CKD and a diagnosis of diabetes may be attributable to misclassification, differences in case definitions, age at CKD diagnosis or the requirement for a confirmatory biopsy in the diagnosis of CKD etiology.

Practice patterns in the population differed from EuroDOPPS: fewer patients had an AV fistula in our cohort compared with EuroDOPPS (73 vs. $80 \%$, respectively) [23]. There was also variation in the dialysis quality indicators: patients in this study had a slightly higher Kt/V than EuroDOPPS patients (1.5 vs. 1.4, respectively), but they were treated with a lower actual blood flow (283 vs. $296 \mathrm{ml} / \mathrm{min}$ ) [10]. The average hemoglobin level $(11 \mathrm{~g} / \mathrm{dl})$ achieved was consistent with previously reported findings from EuroDOPPS [12]. However, the average serum phosphate level achieved was $4.7 \mathrm{mg} / \mathrm{dl}$, which is slightly lower than in EuroDOPPS (5.5 mg/dl) [10]. Serum albumin levels were consistent with those from EuroDOPPS, which also reported a mean of $3.9 \mathrm{~g} / \mathrm{dl}$.

There were minor differences in mortality rates between our study and EuroDOPPS [11]: the crude mortality rates for both Spain and Italy were lower in this study than in EuroDOPPS (11 vs. 15 deaths per 100 patientyears, respectively). However, the reported mortality rate in France was similar to that in EuroDOPPS (13 vs. 14 deaths per 100 patient-years, respectively). Results from this study and EuroDOPPS reported an average length of stay in hospital of 11 days [11].

As expected, we found that incident patients had a higher death rate than prevalent patients (158 vs. 130 deaths per 1,000 patient-years). This difference may reflect survival bias. While incident patients often experience a period of instability during the initial months of dialysis, prevalent patients represent survivors who on in patients randomly selected from 9 European countries 
Table 5. Medication use during the first 6 months of follow-up by country

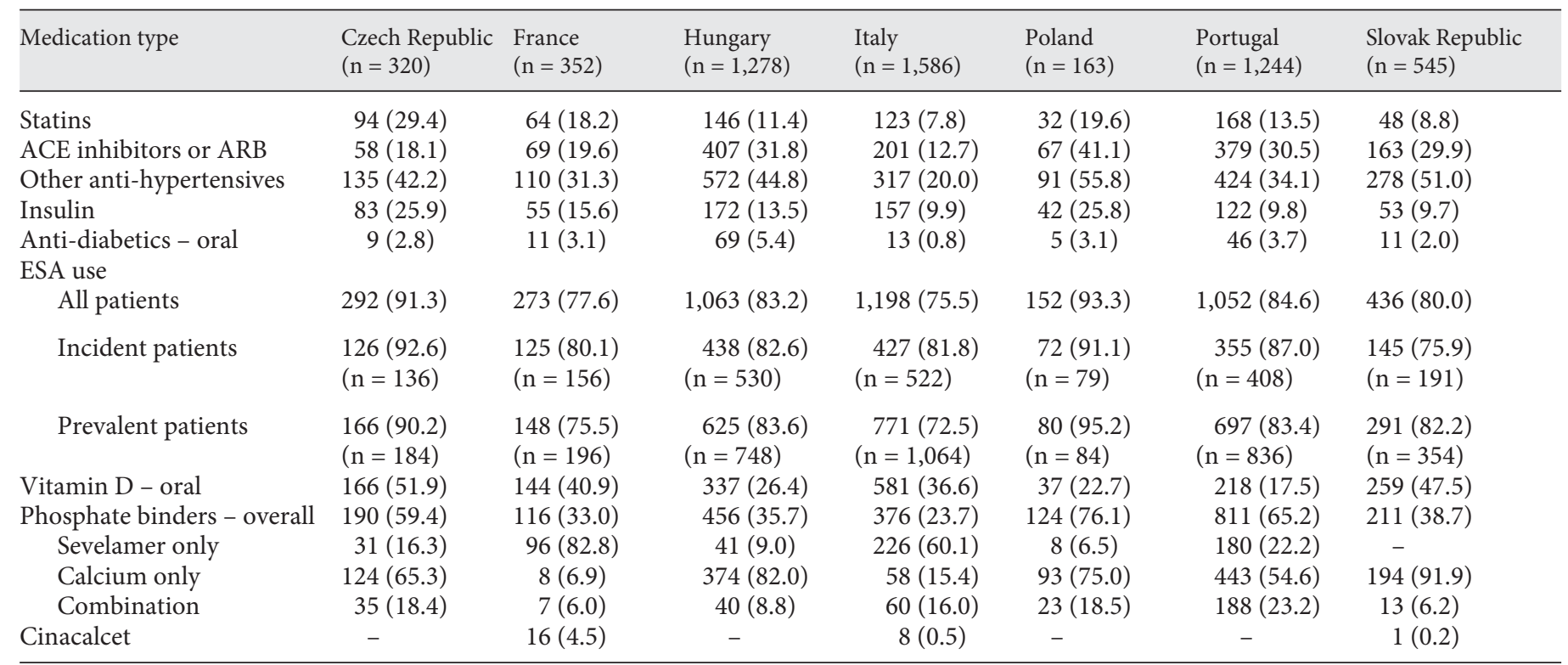

Categorical variables are reported using $\mathrm{n}(\%) .-=$ Missing data; $\mathrm{ACE}=$ angiotensin-converting enzyme; $\mathrm{ARB}=$ angiotensin receptor blocker. Incident patients were on HD therapy $<6$ months at the start of the study; prevalent patients were on HD therapy for $\geq 6$ months.

Table 6. Patient outcome during the entire study period by country (2005-2006)

\begin{tabular}{|c|c|c|c|c|c|c|c|}
\hline Patient outcome & $\begin{array}{l}\text { Czech Republic } \\
(\mathrm{n}=320)\end{array}$ & $\begin{array}{l}\text { France } \\
(\mathrm{n}=352)\end{array}$ & $\begin{array}{l}\text { Hungary } \\
(\mathrm{n}=1,278)\end{array}$ & $\begin{array}{l}\text { Italy } \\
(\mathrm{n}=1,586)\end{array}$ & $\begin{array}{l}\text { Poland } \\
(\mathrm{n}=163)\end{array}$ & $\begin{array}{l}\text { Portugal } \\
(\mathrm{n}=1,244)\end{array}$ & $\begin{array}{l}\text { Slovak Republic } \\
(\mathrm{n}=545)\end{array}$ \\
\hline \multicolumn{8}{|l|}{ Crude death rate } \\
\hline \multicolumn{8}{|l|}{ Age-, gender-, duration of } \\
\hline dialysis-adjusted death rate ${ }^{1}$ & 144 & 134 & 145 & 121 & 147 & 103 & 182 \\
\hline Deaths, $\mathrm{n}(\%)$ & $78(24.4)$ & $87(24.7)$ & $286(22.4)$ & $315(19.9)$ & $35(21.5)$ & $219(17.6)$ & $124(22.8)$ \\
\hline Cardiovascular & $38(48.7)$ & $30(34.5)$ & $69(24.1)$ & $148(47.0)$ & $24(68.6)$ & $74(33.8)$ & $76(61.3)$ \\
\hline Other/unknown & $17(21.8)$ & $46(52.9)$ & $195(68.2)$ & $115(36.5)$ & $5(14.3)$ & $92(42.0)$ & $24(19.4)$ \\
\hline \multicolumn{8}{|l|}{ First hospitalization rate } \\
\hline $\mathrm{n} / 1,000$ patient-years & 1,049 & 492 & 187 & 290 & 1,847 & 324 & 763 \\
\hline Hospitalization $^{2}-\mathrm{n}(\%)$ & $223(69.7)$ & $153(43.5)$ & $279(21.8)$ & $531(33.5)$ & $143(87.7)$ & $452(36.3)$ & $335(61.5)$ \\
\hline \multicolumn{8}{|l|}{ Average duration of hospitalization } \\
\hline per admission, days & $11.6 \pm 10.0$ & $7.2 \pm 8.1$ & $9.5 \pm 9.0$ & $9.7 \pm 9.3$ & $8.9 \pm 12.5$ & $11.9 \pm 20.5$ & $10.4 \pm 8.9$ \\
\hline
\end{tabular}

Continuous variables are reported using means \pm SD. Categorical variables are reported as $\mathrm{n}(\%)$. Adjustment for age, gender and duration of dialysis was performed by including these as covariates in a Poisson regression model.

${ }^{1}$ One patient was excluded from the adjusted death rate calculations due to an outlying value.

${ }^{2}$ Number of patients with at least 1 hospitalization over the course of the study period. 


\begin{tabular}{cccc}
\hline $\begin{array}{l}\text { Slovenia } \\
(\mathrm{n}=168)\end{array}$ & $\begin{array}{l}\text { Spain } \\
(\mathrm{n}=1,707)\end{array}$ & $\begin{array}{l}\text { Turkey } \\
(\mathrm{n}=1,600)\end{array}$ & $\begin{array}{l}\text { Total } \\
(\mathrm{n}=8,963)\end{array}$ \\
\hline $31(18.5)$ & $361(21.1)$ & $123(7.7)$ & $1,190(13.3)$ \\
$46(27.4)$ & $348(20.4)$ & $97(6.1)$ & $1,835(20.5)$ \\
$64(38.1)$ & $518(30.3)$ & $156(9.8)$ & $2,665(29.7)$ \\
$15(8.9)$ & $2(0.1)$ & $148(9.3)$ & $849(9.5)$ \\
$5(3.0)$ & $26(1.5)$ & $37(2.3)$ & $232(2.6)$ \\
& & & \\
$160(95.2)$ & $1,460(85.5)$ & $938(58.6)$ & $7,024(78.4)$ \\
$36(94.7)$ & $726(89.6)$ & $329(62.5)$ & $2,779(81.8)$ \\
$(\mathrm{n}=38)$ & $(\mathrm{n}=810)$ & $(\mathrm{n}=526)$ & $(\mathrm{n}=3,396)$ \\
$124(95.4)$ & $734(81.8)$ & $609(56.7)$ & $4,245(76.3)$ \\
$(\mathrm{n}=130)$ & $(\mathrm{n}=897)$ & $(\mathrm{n}=1,074)$ & $(\mathrm{n}=5,567)$ \\
$74(44.0)$ & $343(20.1)$ & $42(2.6)$ & $2,201(24.6)$ \\
$89(53.0)$ & $981(57.5)$ & $818(51.1)$ & $4,172(46.5)$ \\
$13(14.6)$ & $282(28.7)$ & $38(4.6)$ & $915(21.9)$ \\
$61(68.5)$ & $425(43.3)$ & $733(89.6)$ & $2,513(60.2)$ \\
$15(16.9)$ & $270(27.5)$ & $47(5.7)$ & $698(16.7)$ \\
- & $11(0.6)$ & - & $36(0.4)$ \\
\hline
\end{tabular}

\begin{tabular}{cccc}
\hline $\begin{array}{l}\text { Slovenia } \\
(\mathrm{n}=168)\end{array}$ & $\begin{array}{l}\text { Spain } \\
(\mathrm{n}=1,707)\end{array}$ & $\begin{array}{l}\text { Turkey } \\
(\mathrm{n}=1,600)\end{array}$ & $\begin{array}{l}\text { Total } \\
(\mathrm{n}=8,963)\end{array}$ \\
\hline & & & \\
78 & 143 & 96 & 138 \\
73 & 107 & 115 & 124 \\
$22(13.1)$ & $306(17.9)$ & $206(12.9)$ & $1,678(18.7)$ \\
$13(59.1)$ & $119(38.9)$ & $107(51.9)$ & $698(41.6)$ \\
$1(4.5)$ & $28(9.2)$ & $15(7.3)$ & $135(8.0)$ \\
$1(4.5)$ & $11(3.6)$ & $12(5.8)$ & $124(7.4)$ \\
$7(31.8)$ & $148(48.4)$ & $72(35.0)$ & $721(43.0)$ \\
& & & 344 \\
391 & 491 & 150 & $3,254(36.3)$ \\
$76(45.2)$ & $772(45.2)$ & $290(18.1)$ & $11.1 \pm 14.6$ \\
& & & $438(4.9)$ \\
$10.2 \pm 9.1$ & $12.9 \pm 19.3$ & $12.1 \pm 12.6$ & $1,058(11.8)$ \\
$8(4.8)$ & $135(7.9)$ & $28(1.8)$ & $5,789(64.6)$ \\
$3(1.8)$ & $153(9.0)$ & $444(27.8)$ & \\
$135(80.4)$ & $1,113(65.2)$ & $922(57.6)$ & \\
\hline
\end{tabular}

Epidemiological Study - European

Hemodialysis Patients average had undergone HD for 5 years prior to the study. In line with this assumption, prevalent patients had a higher actual blood flow and Kt/V than incident patients, and they were also more likely to be dialyzed with an AV fistula.

This European study population differed with regard to patient characteristics and practice patterns from US patient populations. For instance, 55\% of patients in USRDS (United States Renal Data System) and 36\% of patients in DOPPS were reported to have diabetes [24], in contrast to the $25 \%$ prevalence of diabetes reported in our study. Moreover, AV fistula use was much more common in this study compared with the US DOPPS population, in both men (76 vs. $41 \%)$ and women (69 vs. $22 \%)$. In addition, an unexpected finding in the ARO population was that incident patients had a higher ESA use than prevalent patients (82 vs. 76\%). We also found differences in mortality rates, which were higher in the US DOPPS cohort [25] (22 vs. 14 deaths per 100 patient-years, respectively). In another US report, Tentori et al. [26] reported that the overall mortality rate in patients treated by the Dialysis Clinic Inc. was lower (17 deaths per 100 patient-years) than that of the 2002 USRDS HD prevalent cohort (21 per 100 patient-years) [27]. However, any apparent differences in mortality should be interpreted with caution due to the lack of adjustment for potentially confounding variables.

To our knowledge, this is the first large epidemiological study to include patients from Eastern Europe and Turkey, who have largely been unaccounted for in previous studies. Consistent with the findings by Levi et al. [28], our study demonstrated large differences in the prevalence of CVD history between Eastern and Western Europe. The strength of this study lies in the granularity of data, particularly with respect to dialysis parameters (actual blood flow and Kt/V) and laboratory parameters. For example, DOPPS contains hemoglobin values measured on a quarterly (DOPPS I and DOPPS II) or a monthly (DOPPS III) basis [3,29], whereas this study evaluated all available measures on hemoglobin.

Study limitations of ARO are that the data were captured from a single private dialysis provider (FME) and data from the UK and Germany were omitted, which restricts the generalizability of our findings. Another limitation was that 44 centers were excluded as a result of inadequate capture of data on key dialysis parameters. Selection bias could theoretically have been introduced into the study if these centers also provided lower quality of care. However, this is unlikely since the missing data were a result of technical issues in the data transfer process and not related to patient selection. 
The data captured in ARO are similar in content to widely published databases in the USA, such as the FMC North America database [30] and the DaVita database [31], both of which include longitudinal patient level data on a wide variety of clinical and laboratory parameters captured during the course of routine care of patients within a single network of dialysis providers. In contrast, however, the ARO database is markedly different from patient registries, such as the ERA-EDTA registry [32], which provides a cross-sectional survey of patient data on an annual basis by linking both national and local renal registries based throughout Europe.

An advantage of databases such as ARO over patient registries is that they provide better granularity in terms of the clinical and laboratory parameters. An important limitation of patient registries is that they often lack data on parameters that may be important confounding factors, and are therefore less useful for answering study questions that require multivariable adjustment. We also found some differences in laboratory parameters which were statistically significant, but clinically unimportant, as a result of the large sample size in the study population. Another advantage of ARO is that it contains longitudinally collected data, which allows time-to-event analysis. A major strength of patient registries lies in the generalizability of results, since patients tend to be more representative of the population of patients from which they were sampled.

The results of this study may help to identify areas for improvement in terms of practice of care. Despite the high prevalence of CVD in the study population, only a minority of these patients received a CVD-related medication at baseline. This may reflect the current lack of evidence concerning the effect of these medications on CVD-related outcome in the HD population, or that trials have failed to demonstrate a benefit (i.e. statins). Thus, in accordance with findings from DOPPS [33], the prevalence of statin use was low. In fact, the results of the $4 \mathrm{D}$ trial of $\mathrm{HD}$ patients [34] and the more recent AURORA trial [35] suggest that CVD in CKD patients differs from that in the general population and that statins are not equally protective. However, others have interpreted the low use of statins in some patients, such as those with a history of myocardial infarction, as underuse [36].

Future studies arising from the ARO initiative will aim to fill gaps in knowledge in the current literature concerning the optimal management of European HD patients. Two recently published papers from ARO described the management of patients with anemia [37] and those with secondary hyperparathyroidism [38].

\section{Acknowledgments}

The authors wish to thank the participating FME centers for collecting the data (online suppl. material, available at www. karger.com/doi/10.1159/000319936). We also wish to thank Elizabeth Ireland (Amgen Ltd., Uxbridge, UK) for providing statistical support for this project, and Susan Wieting and Lucy Hyatt (Amgen $\mathrm{GmbH}$, Zug, Switzerland), who provided editing support. Funding for the ARO CKD Research Initiative was provided by Amgen (Europe) GmbH, Zug, Switzerland.

\section{Disclosure Statement}

Angel L.M. de Francisco has received honoraria and speaker fees from Amgen, Roche and Gambro. Stefan D. Anker has received consultancy fees from Amgen, Vifor International, Fresenius Kabi and honoraria for lectures from Amgen and Vifor International. Bernard Canaud has received research grants from pharmaceutical and dialysis companies (Fresenius, Baxter and Bellco) and the public Ministry of Health, and honoraria from pharmaceutical companies (Amgen, Roche, Janssen Cilag, Shire and Genzyme) as an invited speaker; he holds no stock options and is not a member of a board of directors. Charles Chazot has received honoraria from FME. Tilman B. Drüeke has acted as an advisor/consultant for Amgen, FME, Genzyme, INEOS, Leo, Mitsubishi, Roche and Theraclion; he has received honoraria as a speaker from Amgen, Chugai, Genzyme, Kirin and Roche, and grants/research support from Amgen, Genzyme and Shire. KaiUwe Eckardt has received consulting or lecture fees from Affymax, Amgen, Johnson \& Johnson, Kirin, Roche and Sandoz Hexal. Jürgen Floege has received honoraria and speaker fees from Amgen, Fresenius, Genzyme and Shire. Florian Kronenberg has received honoraria and grant support from Amgen. Iain C. Macdougall has received lecture and consulting fees from Affymax, Amgen, Ortho Biotech, Roche, Shire and Vifor Pharma, and grant support from Affymax, Amgen, Ortho Biotech and Roche. Guntram Schernthaner has received honoraria from Amgen. Peter Stenvinkel is a member of the Scientific Advisory Board at Gambro; he has given lectures at meetings organized by Amgen, Baxter, Genzyme, Roche and Astra, and has received honoraria from Amgen. David C. Wheeler has received honoraria and speaker fees from Amgen, Fresenius, Genzyme, Shire and Vifor Pharmaceuticals. Pedro Aljama has received research grants and participated in advisory boards for Amgen, Janssen-Cilag and Roche. FME.

Daniele Marcelli and Jutta Passlick-Deetjen are employed by

Vasily Belozeroff, Bruno Fouqueray, Joseph Kim and Bart Molemans are full-time employees of Amgen who may own stock and/or stock options in Amgen. 


\section{References}

$\checkmark 1$ Lameire N, Jager K, Van Biesen W, de Bacquer D, Vanholder R: Chronic kidney disease: a European perspective. Kidney Int Suppl 2005;99:S30-S38.

$\checkmark 2$ Bommer J: Prevalence and socio-economic aspects of chronic kidney disease. Nephrol Dial Transplant 2002;17(suppl 11):8-12.

>3 Goodkin DA, Young EW, Kurokawa K, Prutz KG, Levin NW: Mortality among hemodialysis patients in Europe, Japan, and the United states: case-mix effects. Am J Kidney Dis 2004;44:16-21.

4 Pisoni RL, Bragg-Gresham JL, Young EW, Akizawa T, Asano Y, Locatelli F, Bommer J, Cruz JM, Kerr PG, Mendelssohn DC, Held PJ, Port FK: Anemia management and outcomes from 12 countries in the dialysis outcomes and practice patterns study (DOPPS). Am J Kidney Dis 2004;44:305-316.

$\checkmark 5$ Port FK, Orzol SM, Held PJ, Wolfe RA: Trends in treatment and survival for hemodialysis patients in the United States. Am J Kidney Dis 1998;32:S34-S38.

6 Collins AJ, Brenner RM, Ofman JJ, Chi EM, Stuccio-White N, Krishnan M, Solid C, Ofsthun NJ, Lazarus JM: Epoetin alfa use in patients with ESRD: an analysis of recent US prescribing patterns and hemoglobin outcomes. Am J Kidney Dis 2005;46:481-488.

7 Block GA, Klassen PS, Lazarus JM, Ofsthun N, Lowrie EG, Chertow GM: Mineral metabolism, mortality, and morbidity in maintenance hemodialysis. J Am Soc Nephrol 2004; 15:2208-2218.

$\checkmark 8$ Goodkin DA, Bragg-Gresham JL, Koenig KG, Wolfe RA, Akiba T, Andreucci VE, Saito A, Rayner HC, Kurokawa K, Port FK, Held PJ, Young EW: Association of comorbid conditions and mortality in hemodialysis patients in Europe, Japan, and the United States: the dialysis outcomes and practice patterns study (DOPPS). J Am Soc Nephrol 2003; 14:3270-3277

$\checkmark 9$ Lacson E Jr, Wang W, Hakim RM, Teng M, Lazarus JM: Associates of mortality and hospitalization in hemodialysis: potentially actionable laboratory variables and vascular access. Am J Kidney Dis 2009;53:79-90.

$>10$ Hecking E, Bragg-Gresham JL, Rayner HC, Pisoni RL, Andreucci VE, Combe C, Greenwood R, McCullough K, Feldman HI, Young EW, Held PJ, Port FK: Haemodialysis prescription, adherence and nutritional indicators in five European countries: results from the Dialysis Outcomes and Practice Patterns Study (DOPPS). Nephrol Dial Transplant 2004;19:100-107.
11 Rayner HC, Pisoni RL, Bommer J, Canaud B, Hecking E, Locatelli F, Piera L, Bragg-Gresham JL, Feldman HI, Goodkin DA, Gillespie B, Wolfe RA, Held PJ, Port FK: Mortality and hospitalization in haemodialysis patients in five European countries: results from the Dialysis Outcomes and Practice Patterns Study (DOPPS). Nephrol Dial Transplant 2004;19: 108-120.

12 Locatelli F, Pisoni RL, Akizawa T, Cruz JM, Deoreo PB, Lameire NH, Held PJ: Anemia management for hemodialysis patients: Kidney Disease Outcomes Quality Initiative (K/ DOQI) guidelines and Dialysis Outcomes and Practice Patterns Study (DOPPS) findings. Am J Kidney Dis 2004;44:27-33.

13 den Elzen WP, van Manen JG, Boeschoten EW, Krediet RT, Dekker FW: The effect of single and repeatedly high concentrations of C-reactive protein on cardiovascular and non-cardiovascular mortality in patients starting with dialysis. Nephrol Dial Transplant 2006;21:1588-1595.

14 Jager KJ, Merkus MP, Huisman RM, Boeschoten EW, Dekker FW, Korevaar JC, Tijssen JG, Krediet RT: Nutritional status over time in hemodialysis and peritoneal dialysis. J Am Soc Nephrol 2001;12:1272-1279.

15 Merkus MP, Jager KJ, Dekker FW, De Haan RJ, Boeschoten EW, Krediet RT: Predictors of poor outcome in chronic dialysis patients: The Netherlands Cooperative Study on the Adequacy of Dialysis. The NECOSAD Study Group. Am J Kidney Dis 2000;35:69-79.

16 Fernández MJL, Ferreira A, Floege J, Bradbury BD, Benedik M, Pavlovic D, Verbeelen D, Nagy J, Motellథn JL, Carter D, Locatelli F, Cannata-And ${ }_{i}$ JB, COSMOS Group: Results from the initial cross-sectional analysis of the COSMOS baseline population (abstract). Nephrol Dial Transplant 2006;21 (suppl 4):MP358

-17 Marcelli D, Moscardo V, Steil H, Day M, Kirchgessner J, Mitteregger A, Orlandini G, Gatti E: Data management and quality assurance for dialysis network; in Ronco C, La Greca G (eds): Hemodialysis Technology. Contrib Nephrol. Basel, Karger, 2002, vol 137, pp 293-299.

18 Marcelli D, Kirchgessner J, Amato C, Steil H, Mitteregger A, Moscardo V, Carioni C, Orlandini G, Gatti E: EuClid (European Clinical Database): a database comparing different realities. J Nephrol 2001;14(suppl 4):S94-S100

19 Steil H, Amato C, Carioni C, Kirchgessner J, Marcelli D, Mitteregger A, Moscardo V, Orlandini G, Gatti E: EuClid - a medical registry. Methods Inf Med 2004;43:83-88.

20 Rothman KJ, Greenland S: Modern Epidemiology. Philadelphia, Lippincott-Raven, 1998.
21 Daugirdas JT: Second generation logarithmic estimates of single-pool variable volume Kt/V: an analysis of error. J Am Soc Nephrol 1993;4:1205-1213.

22 Stel VS, Van Dijk PC, van Manen JG, Dekker FW, Ansell D, Conte F, Kramar R, Leivestad T, Vela E, Briggs JD, Jager KJ: Prevalence of co-morbidity in different European RRT populations and its effect on access to renal transplantation. Nephrol Dial Transplant 2005;20:2803-2811.

23 Pisoni RL: Vascular access use and outcomes: Results from the DOPPS; in Ronco C, La Greca G (eds): Hemodialysis Technology. Contrib Nephrol. Basel, Karger, 2002, vol 137, pp 13-19.

24 Port FK, Wolfe RA, Hulbert-Shearon TE, McCullough KP, Ashby VB, Held PJ: High dialysis dose is associated with lower mortality among women but not among men. Am J Kidney Dis 2004;43:1014-1023.

25 Bradbury BD, Fissell RB, Albert JM, Anthony MS, Critchlow CW, Pisoni RL, Port FK, Gillespie BW: Predictors of early mortality among incident US hemodialysis patients in the Dialysis Outcomes and Practice Patterns Study (DOPPS). Clin J Am Soc Nephrol 2007;2:89-99.

26 Tentori F, Hunt WC, Stidley CA, Rohrscheib MR, Bedrick EJ, Meyer KB, Johnson HK, Zager PG: Mortality risk among hemodialysis patients receiving different vitamin $\mathrm{D}$ analogs. Kidney Int 2006;70:1858-1865.

27 United States Renal Data System. 2004 Annual Data Reports: Atlas of End-Stage Renal Disease in the United States. National Institutes of Health, National Institute of Diabetes and Digestive and Kidney Diseases, 2004. http://www.usrds.org/atlas_2004.htm (accessed Feb 10, 2010)

28 Levi F, Lucchini F, Negri E, La VC: Trends in mortality from cardiovascular and cerebrovascular diseases in Europe and other areas of the world. Heart 2002;88:119-124.

29 Ethier J, Mendelssohn DC, Elder SJ, Hasegawa T, Akizawa T, Akiba T, Canaud BJ, Pisoni RL: Vascular access use and outcomes: an international perspective from the Dialysis Outcomes and Practice Patterns Study. Nephrol Dial Transplant 2008;23:32193226

-30 Lacson E Jr, Wang W, Lazarus JM, Hakim RM: Hemodialysis facility-based quality-ofcare indicators and facility-specific patient outcomes. Am J Kidney Dis 2009;54:490497.

31 Kalantar-Zadeh K, Lee GH, Miller JE, Streja E, Jing J, Robertson JA, Kovesdy CP: Predictors of hyporesponsiveness to erythropoiesis-stimulating agents in hemodialysis patients. Am J Kidney Dis 2009;53:823-834. 
-32 Couchoud C, Kooman J, Finne P, Leivestad T, Stojceva-Taneva O, Ponikvar JB, Collart F, Kramar R, de Francisco A, Jager KJ: From registry data collection to international comparisons: examples of haemodialysis duration and frequency. Nephrol Dial Transplant 2009;24:217-224.

-33 Andreucci VE, Fissell RB, Bragg-Gresham JL, Ethier J, Greenwood R, Pauly M, Wizemann V, Port FK: Dialysis Outcomes and Practice Patterns Study (DOPPS) data on medications in hemodialysis patients. Am J Kidney Dis 2004;44:61-67.
34 Wanner C, Krane V, Marz W, Olschewski M, Mann JF, Ruf G, Ritz E: Atorvastatin in patients with type 2 diabetes mellitus undergoing hemodialysis. N Engl J Med 2005;353: 238-248.

35 Fellstrom B, Holdaas H, Jardine AG, Svensson MK, Gottlow M, Schmieder RE, Zannad F: Cardiovascular disease in patients with renal disease: the role of statins. Curr Med Res Opin 2009;25:271-285.

36 Winkelmayer WC, Charytan DM, Levin R, Avorn J: Poor short-term survival and low use of cardiovascular medications in elderly dialysis patients after acute myocardial infarction. Am J Kidney Dis 2006;47:301-308.
7 Eckardt KU, Kim J, Kronenberg F, Aljama P, Anker SD, Canaud B, Molemans B, Stenvinkel P, Schernthaner G, Ireland E, Fouqueray B, Macdougall IC: Hemoglobin variability does not predict mortality in European hemodialysis patients. J Am Soc Nephrol 2010; 21 , in press.

38 Floege J, Kim J, Ireland E, Chazot C, Drueke T, de Francisco A, Kronenberg F, Marcelli D, Passlick-Deetjen J, Schernthaner G, Fouqueray B, Wheeler DC, ARO Investigators: Serum iPTH, calcium and phosphate, and the risk of mortality in a European haemodialysis population. Nephrol Dial Transplant 2010 (E-pub ahead of print). 